\title{
Effect of polyamine limitation on DNA synthesis and development of mouse preimplantation embryos in vitro
}

\author{
L. Zwierzchowski, M. Członkowska* and A. Guszkiewicz* \\ Department of Biochemistry and * Laboratory of Transplantation, Institute of Genetics and Animal \\ Breeding, Polish Academy of Sciences, Jastrzebiec, 05-551 Mroków, Poland
}

\begin{abstract}
Summary. In-vitro treatment of preimplantation mouse embryos with spermine and spermidine biosynthesis inhibitor, methylglyoxal-bis-(guanylhydrazone) (MGBG), arrested embryo development at the 8-cell or morula stage. In addition, the embryo DNA synthetic rate, as measured by $\left[{ }^{3} \mathrm{H}\right]$ thymidine incorporation, was strongly inhibited. The inhibition of blastocyst formation and DNA synthesis by MGBG was readily reversible by an exogenous supply of spermine and/or spermidine to the culture medium. DL- $\alpha$-Methylornithine or DL- $\alpha$-difluoromethylornithine ( $\alpha$-DFMO), inhibitors of putrescine biosynthesis, had no effect on embryos cultured for 1 or 2 days, but on the 3rd day embryo DNA synthesis was significantly depressed in the presence of $\alpha$-DFMO. These observations suggest that, during early development of the preimplantation mouse embryo, spermine and spermidine are involved in regulation of embryo growth and DNA synthesis. They may also indicate a role of putrescine at a later stage of mouse embryo development.
\end{abstract}

\section{Introduction}

The naturally occurring polyamines, putrescine, spermidine and spermine, are ubiquitous in biological systems. The stimulation of cell growth and division, both in vivo and in vitro, is associated with an increase of the rate of polyamine biosynthesis (Heby, 1981). Several recent experiments, based on the use of polyamine synthesis inhibitors, have revealed a requirement for polyamines during early development in invertebrates and vertebrates (Brachet, Mamont, Boloukhère, Baltus \& Hancoq-Quertier, 1978; Kusunoki \& Yasumasu, 1978; Heby \& Emanuelsson, 1978; Löwkvist, Heby \& Emanuelsson, 1980; Russell, 1983; Löwkvist, Emanuelsson \& Heby, 1983). However, our present knowledge of the role of polyamines in the development of the mammalian preimplantation embryo is very limited. Alexandre (1979) has shown that in-vitro treatment of mouse embryos with spermidine and spermine biosynthesis inhibitor, methylglyoxal-bis(guanylhydrazone) (MGBG), from the 2-cell stage onwards reversibly arrested cleavage at about the 8-cell stage. Ultrastructural analysis (Gueskens \& Alexandre, 1982) revealed a possible role of polyamines in nucleolar formation. On the other hand, treatment of mouse developing embryos with the putrescine biosynthesis inhibitor, DL- $\alpha$-methylornithine, did not affect cleavage and cavitation of the embryos (Alexandre, 1979).

The purpose of this study was to examine the effects of MGBG and $\alpha$-methylornithine, as well as a new, more potent, inhibitor of putrescine biosynthesis, DL- $\alpha$-difluoromethylornithine ( $\alpha$-DFMO), on DNA synthesis and growth of early mouse embryos cultured in vitro. We have also determined whether an exogenous supply of polyamines was beneficial to embryos incubated with inhibitors of polyamine synthesis.

\section{Materials and Methods}

Source of embryos. Randomly bred CFW mice 4-6 weeks old were the source of embryos. 
Superovulation was induced by intraperitoneal injections of 5-7-5i.u. PMSG (Serogonadotropin: Biowet, Drwalew, Poland) followed by 5-7.5 i.u. hCG (Chorulon: Intervet, Boxmeer, The Netherlands). Immediately after hCG injection females were caged with males and successful matings were verified the following morning by the presence of vaginal plugs. Mice were killed 3 days later by cervical dislocation and embryos were flushed from dissected oviducts using phosphate-buffered isotonic saline (PB1, Whittingham, 1974). Embryos (usually at the 8-cell stage) were pooled and stored in medium PB1 for 30-60 min before starting the culture.

Embryo culture. Eight to 10 embryos were placed in a drop of $100 \mu$ BMOC-3 medium (Brinster, 1972) under paraffin oil (Merck, Darmstadt, F.R.G.; cat. no. 7162) in disposable culture dishes (Falcon, Oxnard, CA, U.S.A.; $3 \mathrm{~cm}$ diameter). The vessels were placed in a sealed chamber, gased with $5 \% \mathrm{CO}_{2}$ in air and incubated for up to 3 days at $37^{\circ} \mathrm{C}$. Media were changed every day. Embryos were inspected daily with a dissecting microscope to monitor the percentage of embryos that developed to the stage of blastocyst.

Inhibitors of polyamine biosynthesis. MGBG (Sigma, St Louis, MO, U.S.A.; $10 \mu \mathrm{M})$, $\alpha$-methylornithine (Calbiochem, San Diego, CA, U.S.A.; $10 \mathrm{~mm}$ ) or $\alpha$-DFMO (kindly donated by Centre de Recherche Merrell, Strasbourg, France; $2 \mathrm{~mm}$ ) were added from the stock solutions at the start of culture as indicated in the text.

DNA synthesis. Embryos were labelled with $12.5 \mu \mathrm{Ci}\left[{ }^{3} \mathrm{H}\right]$ thymidine/ml (Radiochemical Centre, Amersham, U.K.; sp. act. $30 \mathrm{Ci} / \mathrm{mmol}$ ) during the $24 \mathrm{~h}$ before the end of each culture period and then processed for estimation of radioactive precursor incorporated into DNA as described by Roblero, Beas \& Arrau (1981) with slight modifications. After incubation the embryos were washed 5 times in medium PB1 containing unlabelled thymidine 100 times more concentrated than in the culture drop. Then, the embryos were placed in $0.1 \mathrm{ml}$ sterile twice-distilled water and frozen and thawed 5 times to achieve cell rupture. The last thawing was carried out in ice by adding $0.3 \mathrm{ml}$ of a $1 \mathrm{mg} / \mathrm{ml}$ solution of calf thymus DNA (Reanal, Budapest, Hungary) as a carrier. Proteins were digested by incubating the disrupted embryos with $100 \mu \mathrm{g}$ pronase/ml (Calbiochem, San Diego, CA, U.S.A.) for $30 \mathrm{~min}$ at $37^{\circ} \mathrm{C}$, and the nucleic acids were precipitated with cold $10 \%$ trichloroacetic acid (TCA). To remove RNA, the precipitated material was dissolved in $0.4 \mathrm{ml} 0.6 \mathrm{M}-\mathrm{NaOH}$ containing $25 \mathrm{~mm}$-ethylene diamine tetraacetic acid and hydrolysed at $37^{\circ} \mathrm{C}$ for $1 \mathrm{~h}$ followed by precipitation with cold $20 \%$ TCA. The final precipitate was collected on glass microfibre filters (GF/A: Whatman, Springfield Mill, U.K.), washed 5 times with 5\% TCA and once with absolute ethanol. Filters were dried at $60^{\circ} \mathrm{C}$, placed in scintillation vials containing $1 \mathrm{ml}$ hyamine hydroxide (B.D.H., Poole, U.K.) and the radioactivity was counted in a toluene-based scintillation mixture in a Nuclear Chicago Isocap-300 spectrometer.

Statistics. Student's $t$ test was used to compare the mean values between control and treated embryos.

\section{Results}

The results of experiments to characterize the nature of DNA synthesis in mouse embryos cultured in vitro are summarized in Table 1 . The embryo DNA synthesis, as measured by tritiated thymidine incorporation, was highly sensitive to arabinosylcytosine and aphidicolin, drugs which have been reported to inhibit primarily 'replicative' DNA-polymerase- $\alpha$-dependent DNA synthesis (Hübscher, 1983). Hydroxyurea at $1 \mathrm{mM}$ concentration inhibited. $\left[{ }^{3} \mathrm{H}\right]$ thymidine incorporation by about $40 \%$. The inhibition was much higher $(95 \%)$ at $5 \mathrm{~mm}$-hydroxyurea, but at this concentration of the drug about $50 \%$ of the embryos degenerated during culture for 2 days. Moreover, the radioactive, TCA-precipitable product was nearly $100 \%$ destroyed by DNase and hot perchloric acid 
Table 1. Nature of DNA synthesis in mouse embryos in vitro

\begin{tabular}{|c|c|c|}
\hline \multirow[b]{2}{*}{ Treatment } & \multicolumn{2}{|c|}{$\left[{ }^{3} \mathrm{H}\right]$ Thymidine incorporated } \\
\hline & d.p.m./10 embryos $\dagger$ & $\%$ \\
\hline Control & $19302 \pm 618$ & 100 \\
\hline \multicolumn{3}{|l|}{ Added to the culture medium } \\
\hline Arabinosylcytosine $(12.5 \mu \mathrm{g} / \mathrm{ml})$ & $3650 \pm 258^{* * *}$ & 19 \\
\hline Aphidicolin $(2 \mu \mathrm{g} / \mathrm{ml})$ & $2410 \pm 282^{* * *}$ & 12 \\
\hline Hydroxyurea (I mM) & $12122 \pm 289^{* *}$ & 63 \\
\hline Hydroxyurea ( $5 \mathrm{~mm})$ & $1007 \pm 15^{* * *}$ & 5 \\
\hline \multicolumn{3}{|l|}{ Labelled embryos treated with } \\
\hline $5 \% \mathrm{PCA}\left(15 \mathrm{~min}, 90^{\circ} \mathrm{C}\right)$ & $165 \pm 4^{* * * *}$ & 0.8 \\
\hline DNase $\left(0.5 \mathrm{mg} / \mathrm{ml}, 37^{\circ} \mathrm{C}, 30 \mathrm{~min}\right)$ & $55 \pm 3 * * *$ & $0 \cdot 3$ \\
\hline RNase $\left(0.5 \mathrm{mg} / \mathrm{ml}, 37^{\circ} \mathrm{C}, 30 \mathrm{~min}\right)$ & $18141 \pm 380$ & 94 \\
\hline$\alpha$-amylase $\left(0.5 \mathrm{mg} / \mathrm{ml}, 37^{\circ} \mathrm{C}, 30 \mathrm{~min}\right)$ & $15136 \pm 83^{*}$ & 78 \\
\hline \multicolumn{3}{|c|}{$\begin{array}{l}\text { Embryos were cultured from the } 8 \text {-cell stage for } 48 \mathrm{~h} \text {. At } 24 \mathrm{~h} \text { before the end of the } \\
\text { cultures } 12.5 \mu \mathrm{Ci}\left[{ }^{3} \mathrm{H}\right] \text { thymidine/ml were added and on the following day the embryos } \\
\text { were lysed by freezing and thawing and processed as indicated before estimation of the } \\
\text { radioactivity in TCA-insoluble material. }\end{array}$} \\
\hline \multicolumn{3}{|c|}{$\begin{array}{l}\text { Values significantly different from control: }{ }^{*} P<0.02 ;{ }^{* *} P<0.002 ;{ }^{* * *} P<0.001 \\
\text { (Student's } t \text { test). } \\
+ \text { Values are mean }+ \text { s.e.m. of } 4 \text { separate cultures }(10 \text { embryos each })\end{array}$} \\
\hline
\end{tabular}

treatment while it was virtually resistant to $\alpha$-amylase and RNase and completely resistant to $\mathrm{NaOH}$ and pronase (see 'Methods').

To search for the possible involvement of polyamines in the regulation of DNA synthesis and early development of mouse embryos, 3 inhibitors of polyamine biosynthesis were used: $\alpha$-methylornithine and $\alpha$-DFMO, specific inhibitors of ornithine decarboxylase, the enzyme which catalyses the synthesis of putrescine from L-ornithine (Mamont et al., 1976; Metcalf et al., 1978), and MGBG shown to inhibit specifically $S$-adenosyl-L-methionine decarboxylase, the key enzyme on the pathway of spermine and spermidine biosynthesis (Heby, Marton, Wilson \& Gray, 1977). MGBG, at concentration of $10 \mu \mathrm{M}$, induced developmental quiescence of mouse embryos cultured in vitro (Table 2). After culture for 2 days in the presence of the drug the blastocyst formation was inhibited by $80 \%$. The treatment with MGBG arrested most of the embryos before the occurrence of cavitation at the 8-cell or morula stage (not shown). DNA synthesis, as measured by

Table 2. Effect of the inhibition of polyamine biosynthesis on the in-vitro development of mouse embryos and embryo DNA synthesis

\begin{tabular}{lccc}
\hline & $\begin{array}{c}\text { Blastocysts } \\
\text { Medium }\end{array}$ & \multicolumn{2}{c}{$\left[{ }^{3} \mathrm{H}\right]$ Thymidine incorporated } \\
\cline { 3 - 4 } & 84 & d.p.m./10 embryos $\dagger$ & $\%$ \\
\hline Control & 82 & $9316 \pm 713$ & 100 \\
$\alpha$-methylornithine $(10 \mathrm{~mm})$ & 82 & $8943 \pm 268$ & 96 \\
$\alpha$-DFMO $(2 \mathrm{mM})$ & 20 & $9315 \pm 118$ & 100 \\
MGBG $(10 \mu \mathrm{M})$ & 22 & $559 \pm 10^{* * * *}$ & 13 \\
$\alpha$-Methylornithine $(10 \mathrm{mM})+$ MGBG $(10 \mu \mathrm{M})$ & & 6
\end{tabular}

Embryos were cultured from the 8-cell stage as described in 'Methods'. DNA synthesis was measured after incorporation of $\left[{ }^{3} \mathrm{H}\right]$ thymidine during the $24-\mathrm{h}$ period.

$\alpha$-DFMO $=$ DL- $\alpha$-difluoromethylornithine; $\mathbf{M G B G}=$ methylglyoxal-bis-(guanylhydrazone)

† Values are mean \pm s.e.m. of 10-12 separate cultures (10 embryos each).

${ }^{* * *} P<0.001$ compared with control (Student's $t$ test). 
$\left[{ }^{3} \mathrm{H}\right]$ thymidine incorporation, was also inhibited (by $86 \%$ ) in the presence of MGBG. In contrast, the inhibition of putrescine biosynthesis by $\alpha$-methylornithine or $\alpha$-DFMO, which represented the competitive or non-competitive inhibitors of ornithine decarboxylase, at the concentration of 10 or $2 \mathrm{mM}$, respectively, failed to inhibit both blastocyst formation and DNA synthesis (Table 2). In fact, even at a concentration as high as $10 \mathrm{~mm}$, shown to cause the complete, irreversible inhibition of ornithine decarboxylase in other systems, $\alpha$-DFMO affected neither morphological development of embryos nor embryo DNA synthesis (not shown).

Figure 1 shows a representative experiment illustrating the time-course of embryo growth and DNA synthesis in vitro in response to inhibitors of polyamine biosynthesis. In this experiment embryos were cultured for various periods and labelled with $\left[{ }^{3} \mathrm{H}\right]$ thymidine during the last $24 \mathrm{~h}$ of culture. During the first $24 \mathrm{~h}$, treated embryos synthesized DNA at the same rate as controls, but thereafter DNA synthesis declined rapidly in MGBG-treated embryos. On the 2nd day of culture MGBG inhibited the embryo DNA synthesis rate by about $90 \%(P<0.002)$ while on the 3rd day the inhibition was more than $99 \%(P<0.001)$ that of the control value.

$\alpha$-DFMO showed no significant effect on DNA synthesis after 1 or 2 days of culture, but on the 3 rd day the synthetic rate was markedly lower $(P<0.05)$ in $\alpha$-DFMO-treated embryos than in controls. MGBG inhibited in-vitro blastocyst formation by $46 \%, 80 \%$ and $100 \%$ after culture for 1,2 or 3 days, respectively. From Fig. 1 it is also evident that extensive embryo degeneration occurred during the 3 rd day of culture in MGBG-containing media. In the presence of the drug,
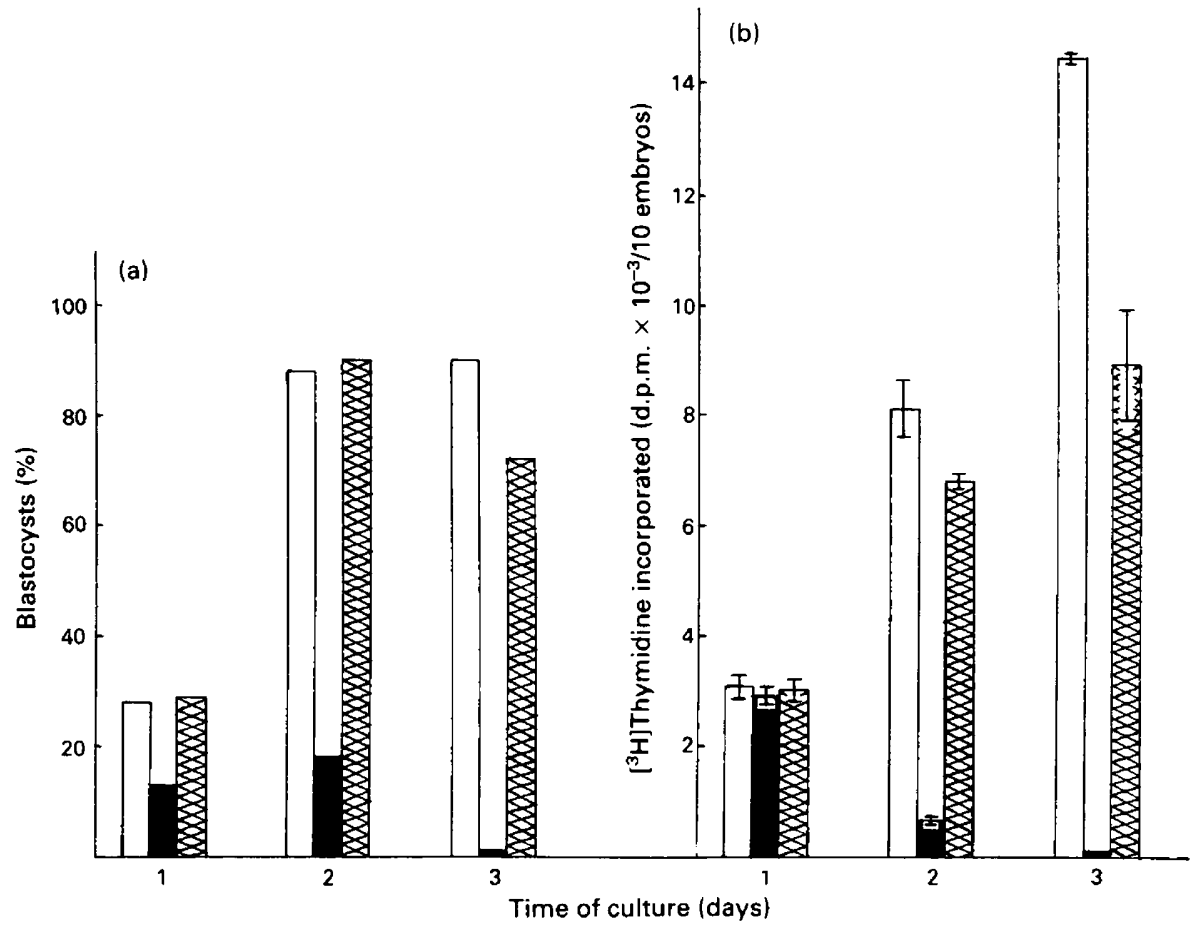

Fig. 1. Time-course of in-vitro mouse embryo growth (a) and DNA synthesis (b) in response to inhibitors of polyamine synthesis. Embryos were cultured from the 8-cell stage for various intervals without inhibitors $(\square)$ or with $10 \mu \mathrm{M}$-MGBG ( $\square$ ) or $2 \mathrm{mM}-\alpha-D F M O(\square \nabla)$. At $24 \mathrm{~h}$ before the end of each culture $12 \cdot 5 \mu \mathrm{Ci}\left[{ }^{3} \mathrm{H}\right]$ thymidine/ml were added and on the following day the embryos were collected and processed for estimation of TCA-insoluble radioactivity as described in 'Methods'. Results are means of 2 separate cultures. 
about $20 \%$ of the embryos were at the blastocyst stage on the 2 nd day while no blastocysts were observed on the 3 rd day. On the other hand, $\alpha$-DFMO showed no adverse effect on embryo development during culture for 2 days, but on the 3 rd day there were $20 \%$ fewer blastocysts than in control cultures.

The addition of polyamines together with inhibitors of their synthesis has often been successfully used to demonstrate the specificity of action of these inhibitors. As shown in Table 3, spermine or spermidine added with MGBG reversed the inhibitory effect of the drug both on embryo development and DNA synthesis. The reversal was almost complete when polyamines were added individually. When added in combination, however, spermine and spermidine were far less effective, possibly because of too high a concentration of total polyamine added. The results in Table 3 also show that both polyamines, individually or together, were nontoxic for mouse embryos at a concentration as high as $2 \times 10^{-3} \mathrm{M}$ (spermidine) or $2 \times 10^{-4} \mathrm{M}$ (spermine).

Table 3. The reversal of inhibition of DNA synthesis and blastocyst formation in mouse embryos by addition of polyamines

\begin{tabular}{lccc}
\hline & $\begin{array}{c}\text { Blastocysts } \\
\text { formed }(\%)\end{array}$ & d.p.m./10 embryos $\dagger$ & $\%$ \\
\cline { 3 - 4 } Medium & 89 & $19263 \pm 53$ & 100 \\
Control & 72 & $20609 \pm 757$ & 107 \\
Spermidine $(2 \mathrm{mM})$ & 83 & $19711 \pm 899$ & 102 \\
Spermine $(0 \cdot 2 \mathrm{mM})$ & 71 & $18542 \pm 1110$ & 96 \\
Spermidine $(2 \mathrm{mM})+$ spermine $(0 \cdot 2 \mathrm{mM})$ & 15 & $3659 \pm 74^{* * *}$ & 19 \\
MGBG $(10 \mu \mathrm{M})$ & 81 & $16537 \pm 606$ & 86 \\
+ Spermidine $(2 \mathrm{mM})$ & 77 & $17484 \pm 717$ & 91 \\
+ Spermine $(0 \cdot 2 \mathrm{mM})$ & 60 & $12315 \pm 213^{* * *}$ & 64 \\
+Spermidine $(2 \mathrm{mM})+$ spermine $(0 \cdot 2 \mathrm{mM})$ & &
\end{tabular}

Embryos were cultured from the 8-cell stage for $48 \mathrm{~h}$ as described in 'Methods'. MGBG and/or polyamines spermidine or spermine were added at the start of cultures.

$\dagger$ Values are mean \pm s.e.m. of 6 separate cultures ( 10 embryos each).

${ }^{* * *} P<0.001$ compared with control (Student's $t$ test).

\section{Discussion}

The present results indicate that the $\left[{ }^{3} \mathrm{H}\right]$ thymidine incorporation into mouse embryos in vitro reflected true nuclear DNA replication, since it was inhibited by aphidicolin, arabinosylcytosine and hydroxyurea and the product was DNase sensitive. Aphidicolin is a specific inhibitor of the 'replicative' DNA polymerase- $\alpha$ (Hübscher, 1983), whereas arabinosylcytosine and hydroxyurea are the drugs that have been claimed to inhibit primarily semiconservative DNA replication (Furth \& Cohen, 1968; Ingaki, Nakamura \& Wakisaka, 1969; Cleaver, 1969). It has been claimed that tritiated thymidine might interfere with the in-vitro development of mouse embryos, due to their sensitivity to irradiation from $\beta$-emitters (Macqueen, 1979; Spindle, Wu \& Pedersen, 1982). We found, however, upon careful examination of over 160 control and labelled embryos, that in the incubation conditions employed in this work $\left[{ }^{3} \mathrm{H}\right]$ thymidine does not interfere with the development of the early mouse embryos. After culture for 2 days, $83 \%$ of embryos developed into blastocysts in the radioactive media and this was not significantly different from that in controls $(88 \%)$. Similarly, there were only $2 \cdot 5$ and $2.9 \%$ degenerate embryos in cultures of embryos in the absence and in the presence of $\left[{ }^{3} \mathrm{H}\right]$ thymidine, respectively.

The results presented in this work suggest that polyamine synthesis is required for growth and development of the mouse embryo. Our present finding that mouse embryo growth in vitro is blocked by the $S$-adenosylmethionine decarboxylase inhibitor (MGBG) but not by ornithine 
decarboxylase inhibitors ( $\alpha$-methylornithine and $\alpha$-DFMO) demonstrates that the synthesis of spermidine and spermine is critical at this early stage of development. MGBG seems to induce a metabolic quiescence of the embryos with regard to both DNA replication and cell proliferation. From the data presented in Fig. 1, it can also be seen that MGBG does not immediately stop the embryo DNA synthesis. After culture for 1 day the amount of $\left[{ }^{3} \mathrm{H}\right]$ thymidine incorporated in the presence of MGBG was not significantly different from that in the controls. The difference became evident, however, after 2 or 3 days of culture. The present data are in agreement with the previous results of Alexandre $(1978,1979)$ showing that the selective inhibition of spermidine and spermine synthesis by MGBG inhibits the development of mouse embryos before the occurrence of cavitation. On the other hand, in contrast to the results obtained with invertebrate and chick embryos (Brachet et al., 1978; Emanuelsson \& Heby, 1978; Löwkvist et al., 1980; Löwkvist et al., 1983), inhibition of ornithine decarboxylase activity by means of $\alpha$-methylornithine or $\alpha$-DFMO exerts no marked effect on mouse embryo development. A slight inhibition observed on the 3rd day of culture seems to be an unspecific or toxic effect since the percentage of blastocysts decreases between Days 2 and 3 of culture. The present results are in line with those of Alexandre (1978) who has found that $\alpha$-methylornithine affected mouse embryo cavitation only at concentrations as high as $20 \mathrm{~mm}$ and that the arrest of development could not be ascribed to a specific inhibition of putrescine synthesis. On the other hand, it has been shown (Fozard et al., 1980) that treatment of pregnant mice with $\alpha$-DFMO (included in the drinking water) suppressed the increase in uterine ornithine decarboxylase activity associated with embryogenesis and arrested embryonic development on Days 7-8 of gestation. From these experiments, however, it is difficult to assess whether the embryo itself was the site where the inhibition of ornithine decarboxylase was functionally important. It has been also shown (Van Winkle \& Campione, 1983) that the outgrowth formation by diapausing mouse blastocysts in vitro was blocked when polyamine synthesis inhibitors, $\alpha$-methylornithine and/or MGBG, were included in the culture media. In the present work we also found a significant inhibitory effect of $\alpha$-DFMO on embryo DNA synthesis on the 3rd day of culture, when most of the embryos are at the late blastocyst stage (Fig. 1). These observations suggest that at later stages of development putrescine biosynthesis might play an important role in mouse embryo development. However, our present results as well as those of Alexandre (1978, 1979) suggest that, in cleavage-stage mouse embryos, spermine and spermidine are the polyamines of primary importance. We have therefore confirmed, with the use of a new, more potent and irreversible inhibitor, that, at this stage of development, the increase of ornithine decarboxylase activity is possibly not a prerequisite for the initiation of embryo DNA synthesis and cell proliferation. The existence of a high pool of endogenous putrescine might be the possible explanation of this phenomenon. This pool might get exhausted at later stages of development thus rendering the embryos sensitive to the inhibitor of putrescine biosynthesis. However, due mainly to the scarcity of embryonic material, no direct information about changes in embryo $S$-adenosyl-L-methionine decarboxylase and ornithine decarboxylase activities or embryo polyamine content during early development in mammals is available.

Reversal of the MGBG effect by exogenous spermine and spermidine, reported in the present work, suggests that at least one of the primary effects of the drug on mouse embryos cultured in vitro is the inhibition of polyamine synthesis. Alexandre (1979) observed that $50 \mu \mathrm{M}$-spermidine and -spermine were toxic to mouse embryos cultured in media containing bovine serum albumin. Nevertheless, we have shown, using $\left[{ }^{3} \mathrm{H}\right]$ thymidine incorporation and percentage of blastocysts formed to assess the development of embryos, that spermidine $(2 \mathrm{~mm})$ or spermine $(0.2 \mathrm{~mm})$ produced no adverse effects, and that both polyamines protected these mouse embryos against MGBG treatment. Our results may support the previous suggestion (Van Winkle \& Campione, 1983) that it is not the polyamines themselves but the products of their oxidation by ruminant plasma amine oxidase, contaminating some preparations of commercially available bovine serum albumin (Tabor \& Tabor, 1972), that are toxic for early mouse embryos.

This work was supported by the Polish Academy of Sciences within the project C-1/2. 


\section{References}

Alexandre, H (1978) Effets de deux inhibiteurs de la biosynthèse des polyamines sur la différenciation primaire de l'oeuf de souris. C. r. hebd. Séanc. Acad. Sci., Paris 286, 1215-1217.

Alexandre, H. (1979) The utilization of an inhibitor of spermidine and spermine synthesis as a tool for the study of the determination of cavitation in the preimplantation mouse embryo. J. Embryol. exp. Morph. 53, 145-162.

Brachet, J., Mamont, P., Boloukhère, M., Baltus, E. \& Hanocq-Quertier, J. (1978) Effets d'un inhibiteur de la synthèse des polyamines sur la morphogénèse chez l'oursin, le chétoptère et l'algue Acetabularia. C. $r$. hebd. Séanc. Acad. Sci., Paris 287, 1289-1292.

Brinster, R.L. (1972) Cultivation of the mammalian embryos. In Growth, Nutrition and Metabolism of Cells in Culture, Vol. II, pp. 251-286. Eds G. H. Rathblat \& V. J. Cristofalo. Academic Press, New York.

Cleaver, J.E. (1969) Repair replication of mammalian cell DNA: effect of compounds that inhibit DNA synthesis or dark repair. Rad. Res. 37, 334-348.

Emanuelsson, H. \& Heby, O. (1978) Inhibition of putrescine synthesis blocks development of the polychete Ophryotrocha labronica at gastrulation. Proc. natn. Acad. Sci. U.S.A. 75, 1039-1042.

Fozard, J.R., Part, M-L., Prakash, N.J., Grove, J., Schechter, P.J., Sjoerdsma, A. \& Koch-Weser, J. (1980) L-Ornithine decarboxylase: an essential role in early mammalian embryogenesis. Science, N.Y. 208, 505-508.

Furth, J.J. \& Cohen, S.S. (1968) Inhibition of mammalian DNA polymerase by the $5^{\prime}$-triphosphate of $1-\beta$-D-arabinofuranosylcytosine and the $5^{\prime}$-triphosphate of $9-\beta-D$-arabinofuranosyladenine. Cancer Res. 28, 2061-2067.

Geuskens, M. \& Alexandre, H. (1982) Effects of an inhibitor of spermidine and spermine synthesis on the uitrastructure of early mouse embryos. Biol. Cell 46, $151-160$.

Heby, O. (1981) Role of polyamines in the control of cell proliferation and differentiation, Differentiation 19, $1-20$.

Heby, O. \& Emanuelsson, H. (1978) Possible involvement of putrescine in nucleolar formation in early embryos. Cell Tissue Res. 194, 103-114.

Heby, O., Marton, L.J., Wilson, C.B. \& Gray, J. (1977) Effect of methylglyoxal-bis-(guanylhydrazone), an inhibitor of spermidine and spermine synthesis on cell cycle traverse. Eur. J. Cancer 73, 1009-1017.

Hübscher, U. (1983) DNA polymerases in prokaryotes and eukaryotes: mode of action and biological implications. Experientia 39, 1-25.
Ingaki, A., Nakamura, T. \& Wakisaka, G. (1969) Studies on the mechanism of action of 1- $\beta-\mathrm{D}$-arabinofuranosylcytosine as an inhibitor of DNA synthesis in human Leukemic Leukocytes. Cancer Res. 29, 2169-2176.

Kusunoki, S. \& Yasumasu, I. (1978) Inhibitory effect of $\alpha$-hydrazinoornithine on egg cleavage in sea urchin eggs. Devl Biol. 67, 336-345.

Löwkvist, B., Heby, O. \& Emanuelsson, H. (1980) Essential role of polyamines in early chick embryo development. J. Embryol. exp. Morph. 60, 83-92.

Löwkvist, B., Emanuelsson, H. \& Heby. O. (1983) Effects of polyamine limitation on nucleolar development and morphology in early chick embryos. Cell Differentiation 12, 19-26.

Macqueen, H.A. (1979) Lethality of radioisotopes in early mouse embryos. J. Embryol. exp. Morph. 52, 203-208.

Mamont, P.S., Böhlen, P., McCann, P.P., Bey, P., Schuber, F. \& Tardif, C. (1976) $\alpha$-Methylornithine, a potent competitive inhibitor of ornithine decarboxylase, blocks proliferation of rat hepatoma cells in culture. Proc. natn. Acad. Sci. U.S.A. 73, 1626-1630.

Metcalf, B.W., Bey, P., Danzin, C., Jung, M.J., Casara, P. \& Vevert, J.P. (1978) Catalytic irreversible inhibition of mammalian ornithine decarboxylase (E.C. 4.1.1.17) by substrate and product analogues. J. Am. Chem. Soc. 100, 2551-2553.

Roblero, L., Beas, F. \& Arrau, J. (1981) Uptake and incorporation of uridine $-{ }^{3} \mathrm{H}$, leucine $-{ }^{3} \mathrm{H}$ and thymidine- ${ }^{3} \mathrm{H}$ by delayed mouse blastocysts under the effect of a human placental protein (UTPH) and its antiserum. Horm. Metab. Res. 13, 188-189.

Russell, D.H. (1983) Microinjection of purified ornithine decarboxylase into Xenopus oocytes selectively stimulates ribosomal RNA synthesis. Proc. natn. Acad. Sci. U.S.A. 80, 1318-1321.

Spindle, A., Wu, K. \& Pedersen, R.A. (1982) Sensitivity of early mouse embryos to $\left[{ }^{3} \mathrm{H}\right]$ thymidine. Expl Cell Res. 142, 397-405.

Tabor, H. \& Tabor, C.W. (1972) Biosynthesis and metabolism of 1,4-diaminobutane, spermidine, spermine and related amines. $A d v$. Enzymol. 36, 203-268.

Van Winkle, L.J. \& Campione, A.L. (1983) Effect of inhibitors of polyamine synthesis on activation of diapausing mouse blastocysts in vitro. J. Reprod. Fert. 68, 437-444.

Whittingham, D.G. (1974) Embryo banks in the future of developmental genetics. Genetics, Priceton 78, $395-402$.

Received 14 March 1985 